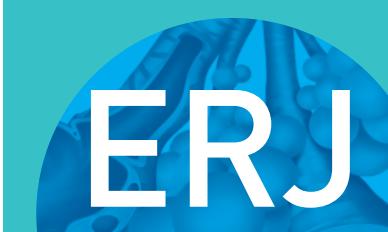

open research
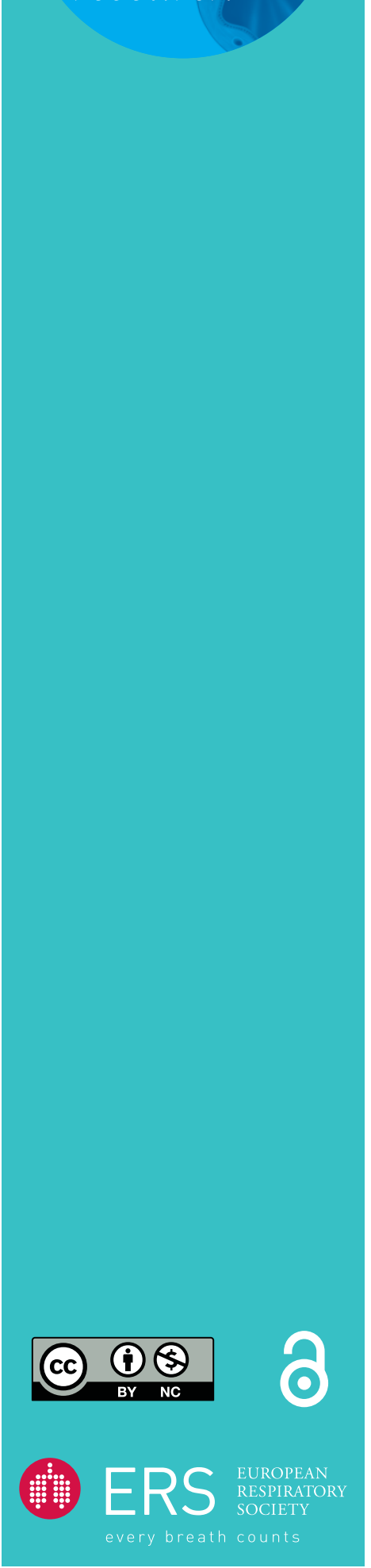

\section{Lung adenocarcinoma patients of young age have lower EGFR mutation rate and poorer efficacy of EGFR tyrosine kinase inhibitors}

\author{
Shang-Gin Wu $\mathrm{W}^{1,2}$, Yih-Leong Chang ${ }^{3}$, Chong-Jen $\mathrm{Yu}^{1,2}$, Pan-Chyr Yang ${ }^{1,2}$ and \\ Jin-Yuan Shih ${ }^{1,2}$
}

Affiliations: ${ }^{1}$ Dept of Internal Medicine, National Taiwan University Hospital, College of Medicine, National Taiwan University, Taiwan. ${ }^{2}$ Graduate Institute of Clinical Medicine, College of Medicine, National Taiwan University, Taipei, Taiwan. ${ }^{3}$ Dept of Pathology, National Taiwan University Hospital, College of Medicine, National Taiwan University, Taipei, Taiwan.

Correspondence: Jin-Yuan Shih, Dept of Internal Medicine, National Taiwan University Hospital, No. 7. Chung-Shan South Road, Taipei 100, Taiwan. E-mail: jyshihantu.edu.tw?\}SUPPL_\$^!"starts-withlstring (//back/child::fn-group/child::fn[1]],'This article has supp')">

ABSTRACT Patients aged $\leqslant 50$ years are rarely diagnosed with nonsmall cell lung cancer. We conducted a retrospective cohort study to understand the mutation status of EGFR and the efficacy of epidermal growth factor receptor tyrosine kinase inhibitor (EGFR-TKI) treatment in young Asian patients with lung adenocarcinoma.

We collected tumour specimens and malignant pleural effusions from lung adenocarcinoma patients from June 2005 to April 2014, recorded their clinical demographic data, and analysed EGFR mutations by reverse transcriptase PCR.

EGFR mutation data were collected from 1039 lung adenocarcinoma patients, including 161 patients aged $\leqslant 50$ years and 878 patients aged $>50$ years. Fewer patients aged $\leqslant 50$ years had EGFR mutations than older patients $(\mathrm{p}=0.043)$, but they showed a higher rate of uncommon $E G F R$ mutations $(\mathrm{p}=0.035)$. A total of 524 patients with EGFR mutations received EGFR-TKI treatment, including 81 patients aged $\leqslant 50$ years. Younger patients had a lower response rate than older patients $(p=0.038)$ and had the shortest progression-free survival compared with other predefined age categories $(p=0.033)$. Multivariate analysis of overall survival revealed age $\leqslant 50$ years as a poor prognostic factor.

In conclusion, fewer Asian patients aged $\leqslant 50$ years had EGFR mutations, but the EGFR mutation types were more uncommon. Age $\leqslant 50$ years is associated with poorer efficacy of EGFR-TKI treatment.

$@$ ERSpublications

Association between age and EGFR mutations http://ow.ly/jV4n30bRBUX

Cite this article as: Wu S-G, Chang Y-L, Yu C-J, et al. Lung adenocarcinoma patients of young age have lower EGFR mutation rate and poorer efficacy of EGFR tyrosine kinase inhibitors. ERJ Open Res 2017; 3: 00092-2016 [https://doi.org/10.1183/23120541.00092-2016].

Received: Aug 172016 | Accepted after revision: May 082017

This article has supplementary material available from openres.ersjournals.com

Support statement: This study was supported by grants NSC101-2314-B-002-167-MY3 and MOST104-2314-B-002-172MY3 (Ministry of Science and Technology, ROC), MOHW103-TDU-PB-211-144002 (Ministry of Health and Welfare), NHRI-EX104-10421BI and NHRI-EX105-10421BI (National Health Research Institutes), NTU104-FTN09 and NTU105-S3032 (National Taiwan University, Taiwan), and NTUHYL104.M001 and NTUHYL105.X004 (National Taiwan University Yun-Lin Branch, Yun-Lin, Taiwan). Funding information for this article has been deposited with the Crossref Funder Registry.

Conflict of interest: Disclosures can be found alongside this article at openres.ersjournals.com

Copyright $\odot$ ERS 2017. This article is open access and distributed under the terms of the Creative Commons Attribution Non-Commercial Licence 4.0. 


\section{Introduction}

Lung cancer is the leading cause of cancer deaths worldwide. Conventional platinum-based chemotherapy is the standard treatment, but the effects are limited. Epidermal growth factor receptor tyrosine kinase inhibitors (EGFR-TKIs) have been shown to provide favourable treatment outcomes in lung cancer patients harbouring activating EGFR mutations. The discovery of oncogenic driver mutations in lung cancer has led to personalised and targeted treatments.

Age-related alterations at the molecular, cellular and physiological levels are associated with carcinogenesis and subsequent cancer growth [1]. Recently, younger patients of different cancer types have been shown to exhibit distinct features in terms of disease characteristics, disease biology and treatment prognosis compared with those of older patients. For example, BRCA1/2 germline mutation or a microsatellite instability phenotype leads to the occurrence of breast cancer or colon cancer at young age. Young patients with breast cancer or colon cancer also have a more aggressive disease process [2-6].

According to the results of the Surveillance, Epidemiology and End Results (SEER) programme, $>60 \%$ of patients are $>60$ years old at initial diagnosis of nonsmall cell lung cancer (NSCLC) in the USA; $<5 \%$ of all NSCLC patients are <50 years old at diagnosis [7]. However, the incidence of lung cancer in young patients has increased gradually [8]. Furthermore, based on analysis of SEER and the California Cancer Registry, younger age as a prognostic factor predicts improved survival among lung cancer patients $[9,10]$.

Some oncogenic driver mutations are associated with age. Among NSCLC patients, EML4-ALK fusion and ROS1 rearrangement are associated with younger age. However, the relationship between EGFR mutation rate and age remains controversial [11-14]. In addition, there are few studies that explore the impact of age on the efficacy of EGFR-TKI treatment $[15,16]$. We therefore conducted a retrospective cohort study to understand EGFR mutation status and EGFR-TKI treatment efficacy for young Asian patients (defined as $\leqslant 50$ years of age) with lung adenocarcinoma in a tertiary hospital in Taiwan.

\section{Materials and methods}

\section{Patients and tissue procurement}

From June 2005 to April 2014, lung cancer tissue and malignant pleural effusion (MPE) specimens were consecutively collected in National Taiwan University Hospital (NTUH). Informed consent for molecular analyses was obtained before tissue collection. The Institutional Review Board of the NTUH Research Ethics Committee approved this study. The tumour specimens included surgically resected lung tumours, bronchoscopy biopsy/brushing specimens and pleural effusions from thoracentesis.

Histological classification of lung adenocarcinoma was performed according to the International Multidisciplinary Classification of Lung Adenocarcinoma criteria [17]. MPE was confirmed by cytology. Pulmonary adenocarcinoma was confirmed by a positive immunohistochemical stain of thyroid transcription factor (TTF)-1 for tumour biopsies or cell blocks of MPEs [17].

All enrolled patients received lung cancer staging work-up, including whole-body bone scintigraphy and computed tomography (CT) of the head, chest and abdomen [18]. Only patients who completed staging work-up were enrolled in this study. Basic demographic information, smoking status and imaging reports were recorded for each patient. Never-smokers were defined as patients who smoked $<100$ cigarettes in their lifetime [19]. Patients who smoked cigarettes within 1 year of diagnosis were defined as current smokers and the remaining patients were regarded as ex-smokers (quit $\geqslant 1$ year ago). The cancer stages and Eastern Cooperative Oncology Group (ECOG) performance status were also recorded [20]. The date of diagnosis, all systemic treatments, including chemotherapy and EGFR-TKIs, and response to treatment were also recorded.

The average age of menopause is 50-51 years in the USA, and 47-50 years in Korea, Lebanon, Singapore, Greece, Morocco, Mexico, Taiwan and Turkey [21]. Therefore, we defined young patients as patients aged $\leqslant 50$ years.

\section{Treatment response evaluation of EGFR-TKIs in lung adenocarcinoma patients}

The patients received single-agent EGFR-TKI daily and no concurrent chemotherapy or radiotherapy for the lung tumours was performed during EGFR-TKI therapy. To evaluate the responses to clinical treatment, the patients received chest radiographs every 2-4 weeks and chest CT scans (including the liver and adrenal glands) every $2-3$ months as routine clinical practice and as needed. A unidimensional method was adopted to evaluate measurable solid tumours according to the Response Evaluation Criteria in Solid Tumors (RECIST) guidelines version 1.1 [22]. Only patients who had measurable target lesions were enrolled so that treatment responses could be evaluated. The objective responses were defined as complete remission, partial response, stable disease and progressive disease [22]. Response rate was defined as the percentage of patients who achieved complete remission or partial response. Disease control rate was defined as the percentage of patients who achieved complete remission, partial response or stable disease. 
Progression-free survival (PFS) was defined as the period from the date of EGFR-TKI treatment initiation to the date of the first objective or clinical sign of disease progression or death. Overall survival was defined as the period from the date of systemic treatment to the date of death.

\section{EGFR mutation analysis}

RNA was extracted from tissue specimens including lung tumours, metastatic sites and malignant effusions with a QIAamp RNA Mini Kit (Qiagen, Hilden, Germany) according to the manufacturer's protocol. Spectrophotometry was used to measure the quantity and quality of the extracted RNA. Tissue specimens were processed for EGFR mutation analysis as described previously [23, 24]. Exons 18-21 of EGFR were amplified by reverse transcriptase PCR with a OneStep RT-PCR Kit (Qiagen) as described previously [25]. Tumours harbouring EGFR exon 19 deletion (del-19) or L858R point mutations are known to show good responses to EGFR-TKIs and both were defined as classical mutations [26]. The other EGFR mutations were detected infrequently and defined as uncommon EGFR mutations.

\section{Statistical analysis}

The Chi-squared test was used for analysis of all categorical variables. The nonparametric Mann-Whitney U-test was used to compare the median ages between two groups. Survival curves were plotted using the Kaplan-Meier method and compared between groups using the log-rank test. To explore the impact of age on EGFR-TKI treatment efficacy, we used age categories in PFS and overall survival analysis: $\leqslant 50,51-60$, 61-70, 71-80 and $>80$ years. Multivariate Cox models were used to estimate adjusted hazard ratios (HRs). Two-sided p-values of $<0.05$ were considered statistically significant. We used SPSS version 17.0 (SPSS, Chicago, IL, USA) for statistical analysis.

\section{Results}

\section{Clinical characteristics of lung adenocarcinoma patients}

From June 2005 to April 2014, we consecutively collected 2680 tissue and MPE specimens, which included 1668 lung adenocarcinoma specimens from 1066 patients. The tissue specimens included 171 surgically resected tumours, 53 bronchoscopic biopsies and 42 bronchial brushing specimens; the majority of the specimens was composed of 1402 MPEs. Of the 1066 patients, specimens from 27 patients were inadequate or insufficient for EGFR mutation analysis, yielding 1039 patients with EGFR mutation test results. Data from some patients were included in our prior studies [25, 27, 28].

Of the 1039 patients, 540 (52.0\%) were female and 742 (71.4\%) were never-smokers. Median (range) age was $65.4(26.8-95.5)$ years. $74.1 \%$ (770 out of 1039) of the patients had stage IV disease at initial diagnosis (table 1). There were $161(15.5 \%)$ patients aged $\leqslant 50$, including: $14(8.7 \%)$ patients with stage I, seven (4.3\%) patients with stage II, 22 (13.7\%) patients with stage III and $118(73.3 \%)$ patients with stage IV at initial diagnosis of lung cancer (table 1 ). Compared with patients aged $>50$ years, younger patients had better performance status $(\mathrm{p}<0.001)$. There were no significant differences in sex $(\mathrm{p}=0.908)$, smoking history $(\mathrm{p}=0.136)$ or initial cancer stages $(\mathrm{p}=0.328)$ between patients aged $\leqslant 50$ and $>50$ years (table 1$)$.

\section{EGFR mutation status}

Of the 1039 lung adenocarcinoma patients, 673 (64.8\%) patients tested positive for EGFR mutations. Females (females $71.5 \%$ versus males $57.5 \%$; $\mathrm{p}<0.001$ ) and never-smokers (never-smokers $71.6 \%$ versus smokers 47.8\%; $\mathrm{p}<0.001$ ) had higher EGFR mutation rates. The EGFR mutation types included 289 (27.8\%) del-19, 288 (27.7\%) L858R and 96 (9.2\%) uncommon mutations (table 2). Among the 673 EGFR mutant patients, there were no differences in EGFR mutation types between never-smokers and ex-/current smokers $(\mathrm{p}=0.145)$ (supplementary table $\mathrm{S} 1$ ). There were 25 patients with exon 18 mutation of EGFR. The rates of exon 18 mutation did not reach a statistical difference between never-smokers (17 out of $531(3.2 \%))$ and smokers (eight out of $142(5.6 \%))(p=0.173)$.

Compared with the patients aged $>50$ years, EGFR mutations were less frequent in younger patients (57.8\% versus $66.1 \%$; $\mathrm{p}=0.043$ ). Interestingly, younger patients had a higher rate of uncommon EGFR mutations than older patients ( $13.7 \%$ versus $8.4 \%$; $\mathrm{p}=0.035)$ (table 2 ).

\section{Clinical characteristics of EGFR-TKI-treated patients with lung adenocarcinoma harbouring EGFR mutations}

As patients harbouring tumours with the de novo T790M mutation are associated with primary resistance to EGFR-TKI treatment $[29,30]$, we excluded five patients with L858R+de novo T790M from this study, all $>50$ years old.

There were 524 EGFR mutant patients who had measurable target lesions and had taken EGFR-TKIs, including 366 who took gefitinib, 137 who took erlotinib and 21 who took afatinib. The demographic 


\begin{tabular}{|c|c|c|c|c|}
\hline & Total patients & Age $\leqslant 50$ years & Age $>50$ years & p-value \\
\hline Subjects & 1039 & $161(15.5)$ & 878 (84.5) & \\
\hline Age years & $65.4(26.8-95.5)$ & $43.8(26.8-49.9)$ & $68.2(50.1-95.5)$ & \\
\hline Sex & & & & 0.908 \\
\hline Female & 540 & $83(51.6)$ & $457(52.1)$ & \\
\hline Male & 499 & 78 (48.4) & 421 (47.9) & \\
\hline Smoking history ${ }^{\#}$ & & & & 0.136 \\
\hline Never-smoker & 742 & 118 (73.3) & $624(71.2)$ & \\
\hline Ex-smoker & 130 & $13(8.1)$ & $117(13.4)$ & \\
\hline Current smoker & 165 & $30(18.6)$ & 135 (15.4) & \\
\hline ECOG PS & & & & $<0.001$ \\
\hline $0-1$ & 887 & 154 (95.7) & 733 (83.5) & \\
\hline $2-4$ & 152 & $7(4.3)$ & 145 (16.5) & \\
\hline Stage at initial diagnosis & & & & 0.328 \\
\hline I & 118 & $14(8.7)$ & 104 (11.8) & \\
\hline II & 45 & $7(4.3)$ & $38(4.3)$ & \\
\hline III & 106 & $22(13.7)$ & $84(9.6)$ & \\
\hline IV & 770 & 118 (73.3) & 652 (74.3) & \\
\hline
\end{tabular}

characteristics of these patients are listed in table 3. Among them, 308 were female (58.8\%) and 419 were never-smokers (80.0\%). Median (range) age was 64.7 (29.5-92.1) years. The EGFR mutation status included 233 del-19, 228 L858R and 63 uncommon mutations (table 4). EGFR-TKIs were taken as first-line treatment by 339 patients (64.7\%), second-line treatment by 117 patients (22.3\%) and subsequent-line (third-line or greater) treatment by 67 patients $(13.0 \%)$.

81 patients $(15.5 \%)$ were aged $\leqslant 50$ years (table 3$)$. Younger patients showed better performance status $(\mathrm{p}=0.002)$, more current smokers $(\mathrm{p}=0.010)$ and more uncommon EGFR mutations $(22.2 \%$ versus $10.2 \%$; $\mathrm{p}=0.009)$ than patients aged $>50$ years. In addition, there were 21 patients who received afatinib treatment. Afatinib was prescribed more frequently to younger patients (aged $\leqslant 50$ years) than to older patients (aged $>50$ years) (8.6\% versus $3.2 \%$ ). Their EGFR mutation types included six del-19, nine L858R and six uncommon mutations. Of the six patients with uncommon EGFR mutations, five had a partial response to EGFR-TKI treatment and one had progressive disease.

\section{Treatment response rate and PFS for EGFR-TKIs among EGFR mutant patients}

Of the 524 EGFR mutant patients who received EGFR-TKI treatment, the response rate was $79.0 \%$ and the PFS was 8.9 (95\% CI 8.21-9.59) months. Patients aged $\leqslant 50$ years had a lower disease response rate $(70.4 \%$ versus $80.6 \% ; \mathrm{p}=0.038)$ and disease control rate $(75.3 \%$ versus $84.8 \% ; \mathrm{p}=0.035)$ than older patients (supplementary table S2).

In addition, PFS for EGFR-TKIs analysed by predefined age categories revealed that the shortest median PFS occurred among patients aged $\leqslant 50$ years ( 7.3 months), followed by those aged $51-60$ years ( 8.7 months), $>80$ years ( 8.8 months), $61-70$ years $(9.6$ months) and $71-80$ years $(10.1$ months) $(\mathrm{p}=0.033)$ (figure 1$)$.

\section{TABLE 2 Difference in EGFR mutations among lung adenocarcinoma patients}

\begin{tabular}{lccccc} 
& Wild-type & Del-19 & L858R & Uncommon & Total \\
\hline $\begin{array}{l}\text { Age years } \\
\leqslant 50\end{array}$ & $68(42.2)$ & $37(23.0)$ & $34(21.1)$ & $22(13.7)$ & 161 \\
$>50$ & $298(33.9)$ & $252(28.7)$ & $254(28.9)$ & $74(8.4)$ & 878 \\
Total & $366(35.2)$ & $289(27.8)$ & $288(27.7)$ & $96(9.2)$ & 1039 \\
\hline
\end{tabular}

Data are presented as $n(\%)$ or $n . p=0.043$ for lung adenocarcinoma patients aged $\leqslant 50$ versus $>50$ years for positive and negative EGFR mutations. $p=0.035$ for lung adenocarcinoma patients aged $\leqslant 50$ versus $>50$ years with tumours harbouring uncommon EGFR mutations. 


\begin{tabular}{|c|c|c|c|c|}
\hline & Total patients & Age $\leqslant 50$ years & Age $>50$ years & p-value \\
\hline Subjects & 524 & 81 (15.5) & 443 (84.5) & \\
\hline Age years & $64.7(29.5-92.1)$ & $43.9(29.5-49.6)$ & $68.1(50.1-92.1)$ & \\
\hline Sex & & & & 0.405 \\
\hline Female & 308 & $51(63.0)$ & 257 (58.0) & \\
\hline Male & 216 & 30 (37.0) & $186(42.0)$ & \\
\hline Smoking history & & & & 0.010 \\
\hline Never-smoker & 419 & 62 (76.5) & $357(80.6)$ & \\
\hline Ex-smoker & 52 & $4(4.9)$ & 48 (10.8) & \\
\hline Current smoker & 53 & 15 (18.5) & $38(8.6)$ & \\
\hline ECOG PS & & & & $0.002^{\#}$ \\
\hline $0-1$ & 449 & 78 (96.3) & 371 (83.7) & \\
\hline $2-4$ & 75 & $3(3.7)$ & $72(16.3)$ & \\
\hline EGFR mutation & & & & 0.009 \\
\hline Del-19 & 233 & 33 (40.7) & $200(45.1)$ & \\
\hline L858R & 228 & 30 (37.0) & 198 (44.7) & \\
\hline Uncommon & 63 & $18(22.2)$ & $45(10.2)$ & \\
\hline EGFR-TKI & & & & 0.051 \\
\hline Gefitinib & 366 & $51(63.0)$ & 315 (71.1) & \\
\hline Erlotinib & 137 & $23(28.4)$ & $114(25.7)$ & \\
\hline Afatinib & 21 & $7(8.6)$ & 14 (3.2) & \\
\hline TKI sequence & & & & 0.140 \\
\hline First-line & 339 & 49 (60.5) & 290 (65.5) & \\
\hline Second-line & 117 & 16 (19.8) & $101(22.8)$ & \\
\hline Third-line or greater & 68 & 16 (19.8) & 52 (11.7) & \\
\hline
\end{tabular}

We stratified the patients into del-19, L858R and uncommon mutations to investigate the impact of age on the effect of EGFR-TKIs for different EGFR mutation types. Among patients with del-19, there were no differences in PFS for EGFR-TKIs between young and old patients (8.3 versus 9.9 months; $\mathrm{p}=0.279$ ) (figure 2a). Among patients with L858R, younger patients had shorter PFS on EGFR-TKI than those aged $>50$ years ( 7.3 versus 9.6 months; $\mathrm{p}=0.003$ ) (figure $2 \mathrm{~b}$ ). For those with uncommon EGFR mutations, there was no significant difference between the two age groups ( 3.0 versus 5.2 months; $\mathrm{p}=0.834$ ) (figure $2 \mathrm{c}$ ).

We then stratified the patients according to sex to investigate the impact of sex on the effect of EGFR-TKIs. Among female patients, younger patients had shorter PFS for EGFR-TKIs than those aged $>50$ years ( 7.4 versus 9.9 months; $\mathrm{p}=0.027$ ) (supplementary figure S1). Among male patients, the difference ( $\leqslant 50$ versus $>50$ years) also showed a similar trend, although not statistically significant (6.9 versus 8.8 months; $\mathrm{p}=0.055$ ) (supplementary figure $\mathrm{S} 2$ ).

As prior reports showed that smoking may impact the treatment efficacy of EGFR-TKIs [31, 32], we analysed the association between the clinical response of patients on EGFR-TKIs and their smoking history. Current smokers (34 out of $53(64.2 \%)$ ) had the lowest response rate, followed by never-smokers (336 out of $419(80.2 \%))$ and ex-smokers (44 out of $52(84.6 \%))(\mathrm{p}=0.015)$. Current smokers (6.9 months) also had the shortest PFS for EGFR-TKIs compared with never-smokers (9.1 months) and ex-smokers (9.4 months) $(\mathrm{p}=0.015)$ (supplementary figure S3). We also stratified the patients according to smoking history and then investigated the impact of age on the effect of EGFR-TKIs. Among never-smokers, younger patients had shorter PFS on EGFR-TKI than those aged $>50$ years (7.7 versus 9.7 months; $\mathrm{p}=0.047$ ) (supplementary figure $\mathrm{S} 4 \mathrm{a}$ ). However, there were no significant differences between age groups among ex-smokers $(\mathrm{p}=0.115)$ and current smokers $(\mathrm{p}=0.148)$ (supplementary figure S4b and $\mathrm{c}$ ).

Multivariate analysis was performed using the Cox regression model for potential predictive factors of PFS, including predefined age categories, sex, smoking history, performance status and EGFR mutation types (table 5). The result showed that the youngest age category (age $\leqslant 50$ years) had a significant shorter PFS compared with all other age categories except for the group aged 51-60 years. In addition, ECOG performance status 2-4 (HR 1.86, 95\% CI 1.38-2.50; $\mathrm{p}<0.001)$ was significantly associated with shorter 


\begin{tabular}{|c|c|c|c|c|}
\hline EGFR mutation & Age $\leqslant 50$ years & Age $>50$ years & Total & EGFR-TKI response \\
\hline G719A & 2 & 1 & 3 & $2 \mathrm{PR}, 1 \mathrm{PD}$ \\
\hline G719D & 0 & 1 & 1 & $1 \mathrm{PD}$ \\
\hline G719S & 1 & 0 & 1 & $1 \mathrm{PR}$ \\
\hline L747P & 0 & 2 & 2 & $1 \mathrm{PR}, 1 \mathrm{PD}$ \\
\hline A763_Y764 ins FQEA & 2 & 0 & 2 & $1 \mathrm{PR}, 1 \mathrm{PD}$ \\
\hline A767-V769 dup ASV & 0 & 4 & 4 & $4 \mathrm{PD}$ \\
\hline S768-D770 dup SVD & 1 & 3 & 4 & $1 \mathrm{SD}, 3 \mathrm{PD}$ \\
\hline V769_D770 ins GSV & 1 & 0 & 1 & $1 \mathrm{PD}$ \\
\hline D770_N771 ins G & 1 & 0 & 1 & $1 \mathrm{PD}$ \\
\hline Del D770 ins GY & 0 & 1 & 1 & $1 \mathrm{PD}$ \\
\hline Del N771 ins KH & 0 & 1 & 1 & $1 \mathrm{PD}$ \\
\hline P772-773H dup $\mathrm{PH}$ & 0 & 1 & 1 & $1 \mathrm{PD}$ \\
\hline $\mathrm{P} 772 \_\mathrm{H} 773$ ins $\mathrm{YNP}+\mathrm{H} 773 \mathrm{Y}$ & 1 & 0 & 1 & $1 \mathrm{PD}$ \\
\hline K806E & 0 & 1 & 1 & $1 \mathrm{PR}$ \\
\hline $\mathrm{R} 831 \mathrm{H}$ & 1 & 0 & 1 & $1 \mathrm{PR}$ \\
\hline L861P & 0 & 1 & 1 & $1 \mathrm{PR}$ \\
\hline L861Q & 0 & 5 & 5 & $2 \mathrm{PR}, 2 \mathrm{SD}, 1 \mathrm{PD}$ \\
\hline L861R & 0 & 1 & 1 & $1 \mathrm{PR}$ \\
\hline G719A+S720F & 0 & 1 & 1 & $1 \mathrm{PR}$ \\
\hline G719A+S768I & 0 & 1 & 1 & $1 \mathrm{PD}$ \\
\hline $\mathrm{G} 719 \mathrm{~A}+\mathrm{V} 769 \mathrm{M}$ & 1 & 0 & 1 & $1 \mathrm{PD}$ \\
\hline G719C+S768I & 0 & 1 & 1 & $1 \mathrm{PR}$ \\
\hline$G 719 D+L 861 Q$ & 0 & 1 & 1 & $1 \mathrm{PD}$ \\
\hline G719S+Q701L+1706T & 0 & 1 & 1 & $1 \mathrm{PR}$ \\
\hline G719S+E709K & 0 & 1 & 1 & $1 \mathrm{PR}$ \\
\hline G719S+L747S & 0 & 1 & 1 & $1 \mathrm{PR}$ \\
\hline G719S+L861Q & 1 & 0 & 1 & $1 \mathrm{PR}$ \\
\hline P772_H773insYNP+H773Y & 1 & 0 & 1 & $1 \mathrm{PD}$ \\
\hline Del-19+K754T & 0 & 1 & 1 & $1 \mathrm{PR}$ \\
\hline Del-19+V769M & 0 & 1 & 1 & $1 \mathrm{PD}$ \\
\hline L858R+E709A & 1 & 0 & 1 & $1 \mathrm{PR}$ \\
\hline$L 858 R+E 709 G$ & 1 & 3 & 4 & $3 \mathrm{PR}, 1 \mathrm{PD}$ \\
\hline $\mathrm{L} 858 \mathrm{R}+\mathrm{K} 754 \mathrm{R}+\mathrm{E} 762 \mathrm{~K}$ & 0 & 1 & 1 & $1 \mathrm{PR}$ \\
\hline L858R+S768I & 1 & 1 & 2 & $2 P R$ \\
\hline L858R+R776H & 0 & 2 & 2 & $2 P R$ \\
\hline L858R+V834L & 1 & 3 & 4 & $2 P R, 2 P D$ \\
\hline L858R+A859S & 0 & 1 & 1 & $1 \mathrm{PR}$ \\
\hline L858R+K860I & 1 & 0 & 1 & $1 \mathrm{PR}$ \\
\hline L858R+A871E & 1 & 0 & 1 & $1 \mathrm{PR}$ \\
\hline$L 861 Q+E 746 G$ & 0 & 1 & 1 & $1 \mathrm{PR}$ \\
\hline $\mathrm{L} 861 \mathrm{Q}+\mathrm{R} 776 \mathrm{H}$ & 0 & 1 & 1 & $1 \mathrm{PD}$ \\
\hline L861R+R831C & 0 & 1 & 1 & $1 \mathrm{PR}$ \\
\hline
\end{tabular}

Data are presented as n. EGFR: epidermal growth factor receptor; TKI: tyrosine kinase inhibitor; PR: partial response; SD: stable disease; PD: progressive disease.

PFS. Classical EGFR mutations, del-19 (HR 0.63, 95\% CI 0.46-0.86; p=0.003) and L858R (HR 0.72, 95\% CI 0.53-0.99; $\mathrm{p}=0.041$ ), were associated with longer PFS.

\section{Overall survival and prognostic factors of EGFR mutant patients treated with EGFR-TKIs}

Univariate analysis of prognostic factors was conducted for the 524 EGFR mutant patients who had taken EGFR-TKIs as shown in table 6 . Stratified by predefined age categories, the shortest median overall survival occurred among patients aged $>80$ years ( 14.3 months), followed by those aged 71-80 years (19.0 months), $\leqslant 50$ years (20.7 months), 61-70 years (26.3 months) and 61-70 years (31.5 months) $(\mathrm{p}<0.001)$ (figure 3). Current smokers (15.4 months) had the shortest overall survival followed by never-smokers (25.0 months) and ex-smokers (30.3 months) ( $\mathrm{p}=0.002)$.

Multivariate analysis was performed using the Cox regression model for potential prognostic factors of overall survival, including predefined age categories, sex, smoking, performance status, EGFR mutation types, EGFR-TKI sequence, platinum use and pemetrexed use (table 6). The result showed that the 


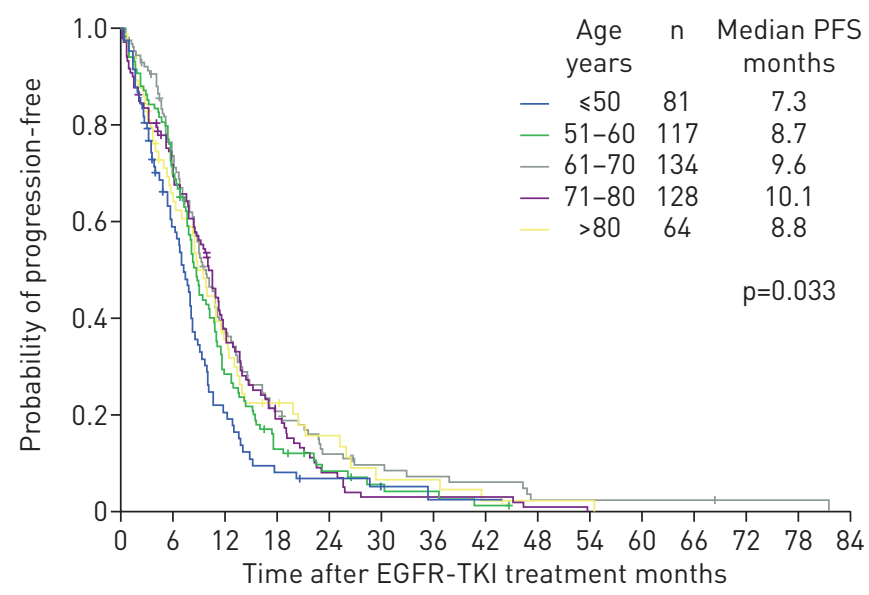

FIGURE 1 Kaplan-Meier curves of epidermal growth factor receptor tyrosine kinase inhibitor (EGFR-TKI) progression-free survival (PFS) for EGFR mutant lung adenocarcinoma patients stratified into predefined age categories: $\leqslant 50,51-60,61-70,71-80$ and $>80$ years. The difference was statistically significant $(p=0.033$, log-rank test).
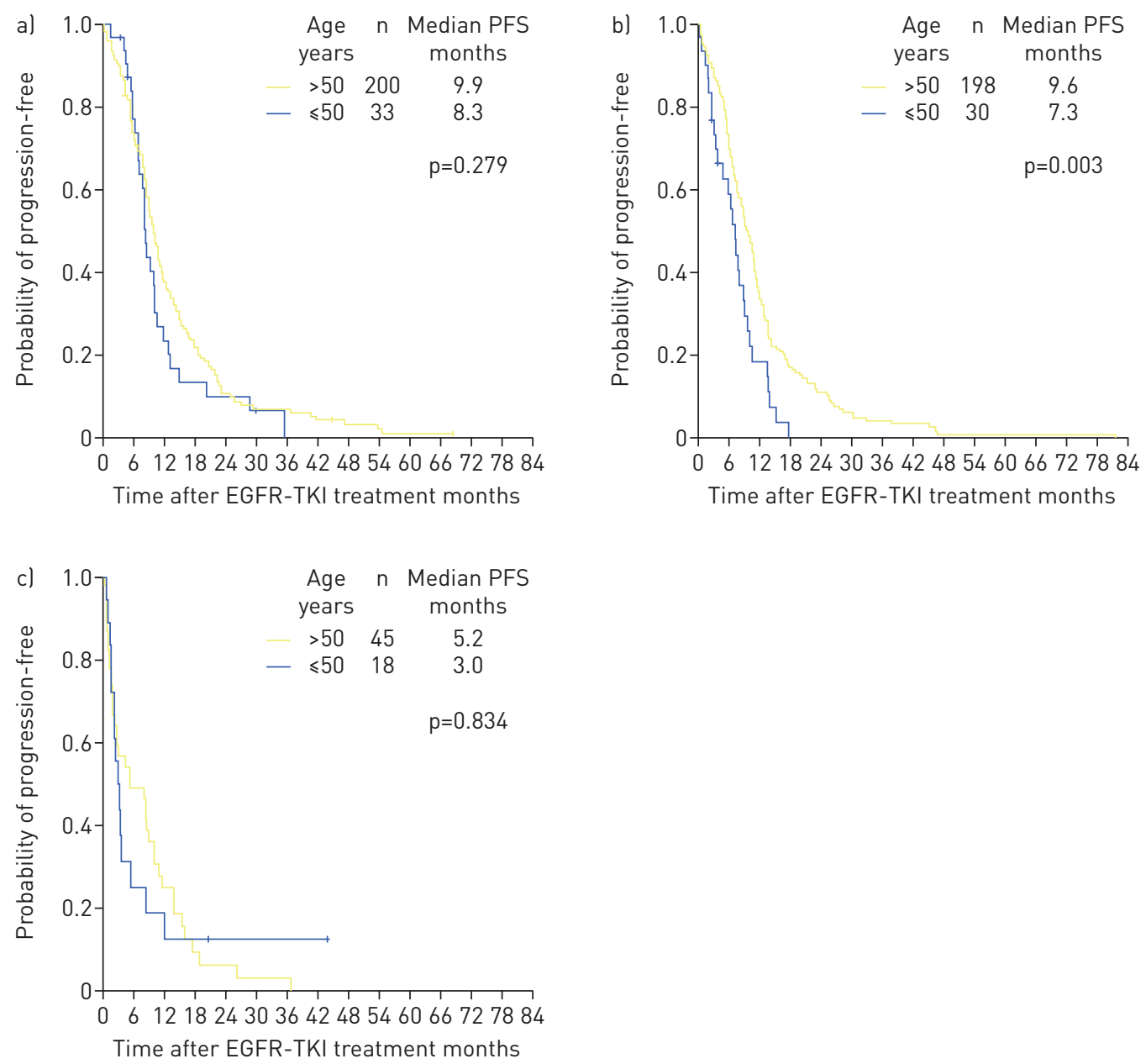

FIGURE 2 Kaplan-Meier curves of epidermal growth factor receptor tyrosine kinase inhibitor (EGFR-TKI) progression-free survival (PFS) were constructed based on different EGFR mutation types. PFS curves of lung adenocarcinoma patients aged $>50$ and $\leqslant 50$ years were plotted separately for patients with a) del-19, b) L858R and c) uncommon EGFR mutations. 
TABLE 5 Multivariate analysis of predictive factors for progression-free survival (PFS) in EGFR mutant patients treated with epidermal growth factor receptor tyrosine kinase inhibitors (EGFR-TKIs)

\begin{tabular}{|c|c|c|c|c|c|}
\hline \multirow[t]{2}{*}{ Factors } & \multirow[t]{2}{*}{ Patients n } & \multirow[t]{2}{*}{ Median PFS months } & \multirow[t]{2}{*}{ Univariate analysis $p$-value } & \multicolumn{2}{|c|}{ Multivariate analysis } \\
\hline & & & & Hazard ratio $(95 \% \mathrm{CI})$ & p-value \\
\hline Age years & & & 0.033 & & \\
\hline $51-60$ & 117 & 8.7 & & $0.80(0.59-1.08)$ & 0.144 \\
\hline $61-70$ & 134 & 9.6 & & $0.66(0.49-0.90)$ & 0.009 \\
\hline $71-80$ & 128 & 10.1 & & $0.69(0.50-0.93)$ & 0.016 \\
\hline Female & 308 & 9.1 & & 1 & \\
\hline Male & 216 & 8.7 & & $1.09(0.88-1.36)$ & 0.428 \\
\hline Smoking history & & & 0.015 & & \\
\hline Never-smoker & 419 & 9.1 & & 1 & \\
\hline Ex-smoker & 52 & 9.4 & & $0.94(0.66-1.32)$ & 0.705 \\
\hline Current smoker & 53 & 6.9 & & $1.40(1.00-1.96)$ & 0.052 \\
\hline Uncommon & 63 & 3.6 & & 1 & \\
\hline Del-19 & 233 & 9.7 & & $0.63(0.46-0.86)$ & 0.003 \\
\hline L858R & 228 & 9.1 & & $0.72(0.53-0.99)$ & 0.041 \\
\hline TKI sequence & & & 0.487 & & \\
\hline First-line & 339 & 9.0 & & 1 & \\
\hline Second-line & 117 & 8.5 & & 0.89 (0.70-1.13) & 0.336 \\
\hline Third-line or greater & 68 & 9.0 & & $0.94(0.71-1.24)$ & 0.643 \\
\hline
\end{tabular}

youngest age category (age $\leqslant 50$ years) had a significantly shorter overall survival compared with the age groups of 51-60 and 61-70 years. In addition, ECOG performance status 2-4 (HR 2.84, 95\% CI 2.13-3.78; $\mathrm{p}<0.001$ ) was significantly associated with shorter overall survival. Pemetrexed use was a favourable prognostic factor (HR 0.57, 95\% CI 0.45-0.72; $\mathrm{p}<0.001$ ).

\section{Discussion}

Lung adenocarcinoma patients aged $\leqslant 50$ years had a shorter PFS and a lower disease control rate for EGFR-TKIs than those aged $>50$ years. Age $\leqslant 50$ years also predicts a poor overall survival. In addition, lung adenocarcinoma patients aged $\leqslant 50$ years had different EGFR mutations compared with older patients. Younger lung adenocarcinoma patients had tumours with a lower EGFR mutation rate but more uncommon mutation types. Age $\leqslant 50$ years and uncommon EGFR mutations were both independent predictive factors of EGFR-TKI response and were associated with a shorter PFS.

Prior studies reported that older patients have higher response rates to EGFR-TKI and longer overall survival [16, 33]. Hsu et al. [34] also noted that lung adenocarcinoma patients aged $\leqslant 45$ years have a shorter PFS (6.0 months) and poorer treatment response to EGFR-TKIs compared with the general population. This finding is compatible with the present study. The disease control rate for EGFR-TKIs was lower in patients aged $\leqslant 50$ years than in those $>50$ years. We showed that age $\leqslant 50$ years was an unfavourable prognostic factor for PFS on EGFR-TKI use compared against all other older age cohorts as well as for overall survival compared with patients aged 51-70 years according to the multivariate analysis.

However, Wheatley-Price et al. [15] did not find age as a significant variable of response rate, PFS and overall survival for erlotinib treatment according to retrospective analysis of the BR.21 trial, which enrolled unselected patients with the majority having EGFR wild-type. The controversial conclusion of the previous studies might stem from the use of different study designs and the small sample size. Variations in the definitions of young age between different studies may also contribute to heterogeneous results. In addition, the present study took EGFR mutation status into consideration for all enrolled patients. EGFR mutation is the most important factor in determining the effect of EGFR-TKIs. Our study enrolled a larger 
TABLE 6 Multivariate analysis of prognostic factors for overall survival in EGFR mutant patients treated with epidermal growth factor receptor tyrosine kinase inhibitors (EGFR-TKIs)

\begin{tabular}{|c|c|c|c|c|c|}
\hline \multirow[t]{2}{*}{ Factors } & \multirow[t]{2}{*}{ Patients $\mathbf{n}$} & \multirow[t]{2}{*}{ Median overall survival months } & \multirow[t]{2}{*}{ Univariate analysis $p$-value } & \multicolumn{2}{|c|}{ Multivariate analysis } \\
\hline & & & & Hazard ratio $(95 \% \mathrm{CI})$ & p-value \\
\hline Age years & & & $<0.001$ & & \\
\hline $51-60$ & 117 & 31.5 & & $0.66(0.47-0.92)$ & 0.015 \\
\hline $61-70$ & 134 & 26.3 & & $0.69(0.50-0.95)$ & 0.025 \\
\hline $71-80$ & 128 & 19.0 & & $0.82(0.59-1.15)$ & 0.246 \\
\hline Female & 308 & 25.3 & & 1 & \\
\hline Male & 216 & 22.4 & & $1.25(0.99-1.57)$ & 0.065 \\
\hline Smoking history & & & 0.002 & & \\
\hline Never-smoker & 419 & 25.0 & & 1 & \\
\hline Ex-smoker & 52 & 30.3 & & $0.96(0.67-1.37)$ & 0.801 \\
\hline Current smoker & 53 & 15.4 & & $1.66(1.17-2.36)$ & 0.005 \\
\hline Uncommon & 63 & 19.0 & & 1 & \\
\hline Del-19 & 233 & 27.9 & & $0.81(0.59-1.11)$ & 0.193 \\
\hline L858R & 228 & 23.1 & & $0.93(0.68-1.27)$ & 0.634 \\
\hline TKI sequence & & & $<0.001$ & & \\
\hline First-line & 340 & 19.5 & & 1 & \\
\hline Second-line & 117 & 28.0 & & $0.70(0.54-0.91)$ & 0.007 \\
\hline Third-line or greater & 67 & 34.7 & & $0.58(0.43-0.78)$ & $<0.001$ \\
\hline Platinum use & & & $<0.001$ & & \\
\hline No & 224 & 15.4 & & 1 & \\
\hline Yes & 300 & 30.3 & & $0.85(0.65-1.11)$ & 0.232 \\
\hline Pemetrexed use & & & $<0.001$ & & \\
\hline No & 252 & 15.2 & & 1 & \\
\hline Yes & 272 & 32.2 & & $0.57(0.45-0.72)$ & $<0.001$ \\
\hline
\end{tabular}

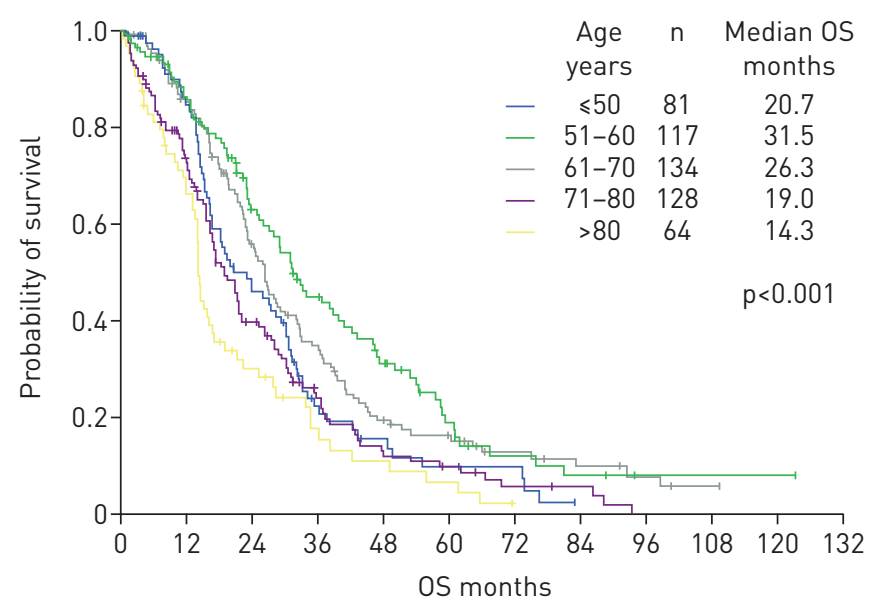

FIGURE 3 Kaplan-Meier survival curves of overall survival (OS) for EGFR mutant lung adenocarcinoma patients who received epidermal growth factor receptor tyrosine kinase inhibitor treatment stratified into predefined age categories: $\leqslant 50,51-60,61-70,71-80$ and $>80$ years. The difference was statistically significant ( $p<0.001$, log-rank test). 
series of patients with complete EGFR mutation reports, and the impact of age on PFS and overall survival was also determined based on predefined age categories for EGFR-TKI-treated patients.

The definitive mechanism for the impact of age on the efficacy of EGFR-TKIs is unknown. The present study showed that EGFR mutant patients aged $\leqslant 50$ years have more uncommon EGFR mutations. The uncommon EGFR mutation rate of the whole study population was $9.5 \%$, which was comparable to $\sim 10 \%$ reported in previous studies [35, 36]. Compared with patients with L858R or del-19, patients with uncommon EGFR mutations had a lower response rate and shorter PFS [28, 37]. This may indirectly confirm the poorer EGFR-TKI treatment outcome among young patients [38]. In addition, most of the patients enrolled in this study received first-generation EGFR-TKIs. The second-generation EGFR-TKI afatinib has been shown to be active in patients with some uncommon EGFR mutations [39]. Larger cohort studies are necessary to clarify the complex mechanism.

Interestingly, the present study showed the most significant difference of PFS in patients with the L858R mutation after stratifying by EGFR mutation types. The different subtypes of EGFR mutations may cause different clinical characteristics and treatment prognosis for EGFR-TKIs [25]. More studies are needed to investigate the complex interactions between EGFR-TKI efficacy and the different EGFR mutation types.

The impact of age on oncogenic gene alteration has been explored for different cancers. The present study showed a lower EGFR mutation rate in patients aged $\leqslant 50$ years, which was compatible with prior studies. EGFR mutations accumulate with age in lung cancer patients [11, 12]. The possible mechanism that results in carcinogenesis proceeds through the accumulation of genetic changes. Cancer cells accumulate such genetic alterations over time [40]. However, some studies did not reach the same conclusion [13, 14]. Recently, SACHER et al. [14] showed that the frequency of targetable genomic alteration was highest among younger patients $(<40$ years) and steadily decreased with age. However, younger patients had more EGFR mutations than older patients [14]. Larger studies are necessary to address the issue in the future.

For Asian patients, the PIONEER study detected an EGFR mutation rate of 51.4\% in lung adenocarcinoma samples (biopsy, surgical specimen or cytology) using the Scorpion amplification refractory mutation system [36]. The study reported that the EGFR mutation rate of lung adenocarcinoma patients in Taiwan was higher, up to $62.1 \%$ [36]. The present study showed that the EGFR mutation rate was $64.8 \%$, which was also higher than the average EGFR mutation rate, but comparable to the Taiwanese data of the PIONEER study. The discrepancy is likely due to differences in specimen collection for EGFR mutation analysis. Our prior study reported that patients with lung adenocarcinoma MPEs had a higher EGFR mutation rate than surgically resected specimens $[25,27]$. In addition, we collected TTF-1-positive tissue samples that are known to have higher EGFR mutation rates than TTF-1-negative tissue samples [41]. Furthermore, different EGFR mutation detection methods may also contribute to the difference.

Prior reports showed that smoking may lower the effects of EGFR-TKI treatment in vitro [42] and in clinical observation studies $[31,32]$. The current study also showed that smoking had an impact on EGFR-TKI treatment response. More patients may be necessary to elucidate the inconspicuous effect and the possible mechanism.

The study has some limitations. First, although the current study enrolled a large series of EGFR mutant patients, the enrolled patients were all Asians, known to have a higher EGFR mutation rate. The result should be confirmed in other areas of the world, especially where lung adenocarcinoma has a low EGFR mutation incidence. Second, we did not examine all reported gene alterations that caused primary resistance to EGFR-TKIs, such as de novo MET amplification [43], KRAS mutations [44] or loss of PTEN [45]. MPEs are not suitable for fluorescence in situ hybridisation assays to detect MET amplification and the availability of cancer tissue samples in this cohort was limited. In addition, EGFR and KRAS mutations are mutually exclusive $[46,47]$. In the current study, we chose to focus on EGFR mutant patients to dissect the impact of age on EGFR-TKI efficacy. Third, we confirmed the diagnosis of lung adenocarcinoma based on TTF-1 positivity. As not all lung adenocarcinomas express TTF-1, this may represent a selection bias. Fourth, we did not compare the smoking of patients of different ages expressed in pack-years because some detailed smoking information was missing from the retrospective records. We just adjusted the smoking factor in treatment efficacy by never-, ex- and current smokers. Fifth, our analyses did not differentiate between the International Association for the Study of Lung Cancer/American Thoracic Society/European Respiratory Society lung adenocarcinoma subtypes for small biopsies/cytology and resection specimens, different lines of EGFR-TKI usage as well as the different EGFR-TKIs used, and a potential time period bias which may have influenced therapeutic strategies and thereby outcome over the long study period has not been further explored.

In conclusion, younger patients had less EGFR mutations but more uncommon EGFR mutations. Aged $\leqslant 50$ years is associated with poorer efficacy of EGFR-TKI treatment. 


\section{Acknowledgements}

The authors would like to thank the Dept of Medical Research at the National Taiwan University Hospital (Taipei, Taiwan) for providing laboratory facilities. We thank Shu-yi Huang (Dept of Medical Research, National Taiwan University Hospital, Taipei, Taiwan) for help in English editing in the revised manuscript.

Author contributions: S-G. Wu and J-Y. Shih had full access to all the data in the study and take responsibility for the integrity of the data and the accuracy of the data analysis. Study concept and design: S-G. Wu, P-C. Yang and J-Y. Shih. Acquisition, analysis or interpretation of data: S-G. Wu, Y-L. Chang, C-J. Yu and J-Y. Shih. Drafting of the manuscript: S-G. Wu, C-J. Yu and J-Y. Shih. Critical revision of the manuscript for important intellectual content: S-G. Wu, P-C. Yang and J-Y. Shih. Statistical analysis: S-G. Wu, J-Y. Shih. Obtained funding: S-G. Wu and J-Y. Shih. Administrative, technical or material support: All authors. Study supervision: C-J. Yu, P-C. Yang and J-Y. Shih.

\section{References}

1 Anisimov VN. Biology of aging and cancer. Cancer Control 2007; 14: 23-31.

2 Gryfe R, Kim H, Hsieh ET, et al. Tumor microsatellite instability and clinical outcome in young patients with colorectal cancer. N Engl J Med 2000; 342: 69-77.

3 Liu B, Farrington SM, Petersen GM, et al. Genetic instability occurs in the majority of young patients with colorectal cancer. Nat Med 1995; 1: 348-352.

4 Azim HA Jr, Michiels S, Bedard PL, et al. Elucidating prognosis and biology of breast cancer arising in young women using gene expression profiling. Clin Cancer Res 2012; 18: 1341-1351.

5 Cancello G, Maisonneuve P, Rotmensz N, et al. Prognosis and adjuvant treatment effects in selected breast cancer subtypes of very young women (<35 years) with operable breast cancer. Ann Oncol 2010; 21: 1974-1981.

6 Azim HA, Partridge AH. Biology of breast cancer in young women. Breast Cancer Res 2014; 16: 427.

7 National Cancer Institute. Surveillance, Epidemiology and End Results Program. Cancer Stat Facts: Lung and Bronchus Cancer. 2014. http://seer.cancer.gov/statfacts/html/lungb.html Date last accessed: May 20, 2017.

8 Marugame T, Yoshimi I, Kamo K, et al. Trends in lung cancer mortality among young adults in Japan. Jpn J Clin Oncol 2005; 35: 177-180.

9 Lara MS, Brunson A, Wun T, et al. Predictors of survival for younger patients less than 50 years of age with non-small cell lung cancer (NSCLC): a California Cancer Registry analysis. Lung Cancer 2014; 85: 264-269.

10 Subramanian J, Morgensztern D, Goodgame B, et al. Distinctive characteristics of non-small cell lung cancer (NSCLC) in the young: a Surveillance, Epidemiology, and End Results (SEER) analysis. J Thorac Oncol 2010; 5: 23-28.

11 Choi YH, Lee JK, Kang HJ, et al. Association between age at diagnosis and the presence of EGFR mutations in female patients with resected non-small cell lung cancer. J Thorac Oncol 2010; 5: 1949-1952.

12 Ueno T, Toyooka S, Suda K, et al. Impact of age on epidermal growth factor receptor mutation in lung cancer. Lung Cancer 2012; 78: 207-211.

13 Serizawa M, Koh Y, Kenmotsu H, et al. Assessment of mutational profile of Japanese lung adenocarcinoma patients by multitarget assays: a prospective, single-institute study. Cancer 2014; 120: 1471-1481.

14 Sacher AG, Dahlberg SE, Heng J, et al. Association between younger age and targetable genomic alterations and prognosis in non-small-cell lung cancer. JAMA Oncol 2016; 2: 313-320.

15 Wheatley-Price P, Ding K, Seymour L, et al. Erlotinib for advanced non-small-cell lung cancer in the elderly: an analysis of the National Cancer Institute of Canada Clinical Trials Group Study BR.21. J Clin Oncol 2008; 26: 2350-2357.

16 Thatcher N, Chang A, Parikh P, et al. Gefitinib plus best supportive care in previously treated patients with refractory advanced non-small-cell lung cancer: results from a randomised, placebo-controlled, multicentre study (Iressa Survival Evaluation in Lung Cancer). Lancet 2005; 366: 1527-1537.

17 Travis WD, Brambilla E, Noguchi M, et al. International Association for the Study of Lung Cancer/American Thoracic Society/European Respiratory Society international multidisciplinary classification of lung adenocarcinoma. J Thorac Oncol 2011; 6: 244-285.

18 Goldstraw P, Chansky K, Crowley J, et al. The IASLC Lung Cancer Staging Project: proposals for revision of the TNM stage groupings in the forthcoming (eighth) edition of the TNM classification for lung cancer. $J$ Thorac Oncol 2016; 11: 39-51.

19 Centers for Disease Control and Prevention. Cigarette smoking among adults - United States, 2006. MMWR Morb Mortal Wkly Rep 2007; 56: 1157-1161.

20 Oken MM, Creech RH, Tormey DC, et al. Toxicity and response criteria of the Eastern Cooperative Oncology Group. Am J Clin Oncol 1982; 5: 649-655.

21 Nelson HD. Menopause. Lancet 2008; 371: 760-770.

22 Eisenhauer EA, Therasse P, Bogaerts J, et al. New response evaluation criteria in solid tumours: revised RECIST guideline (version 1.1). Eur J Cancer 2009; 45: 228-247.

23 Tsai TH, Yang CY, Ho CC, et al. Multi-gene analyses from waste brushing specimens for patients with peripheral lung cancer receiving EBUS-assisted bronchoscopy. Lung Cancer 2013; 82: 420-425.

24 Tsai TH, Su KY, Wu SG, et al. RNA is favourable for analysing EGFR mutations in malignant pleural effusion of lung cancer. Eur Respir J 2012; 39: 677-684.

25 Wu SG, Gow $\mathrm{CH}$, Yu CJ, et al. Frequent epidermal growth factor receptor gene mutations in malignant pleural effusion of lung adenocarcinoma. Eur Respir J 2008; 32: 924-930.

26 Yatabe Y, Mitsudomi T. Epidermal growth factor receptor mutations in lung cancers. Pathol Int 2007; 57: 233-244.

27 Wu SG, Yu CJ, Tsai MF, et al. Survival of lung adenocarcinoma patients with malignant pleural effusion. Eur Respir J 2013; 41: 1409-1418.

28 Wu JY, Yu CJ, Chang YC, et al. Effectiveness of tyrosine kinase inhibitors on "uncommon" epidermal growth factor receptor mutations of unknown clinical significance in non-small cell lung cancer. Clin Cancer Res 2011; 17: $3812-3821$ 
Kobayashi S, Boggon TJ, Dayaram T, et al. EGFR mutation and resistance of non-small-cell lung cancer to gefitinib. N Engl J Med 2005; 352: 786-792.

30 Shih JY, Gow CH, Yang PC. EGFR mutation conferring primary resistance to gefitinib in non-small-cell lung cancer. N Engl J Med 2005; 353: 207-208.

31 Gou LY, Niu FY, Wu YL, et al. Differences in driver genes between smoking-related and non-smoking-related lung cancer in the Chinese population. Cancer 2015; 121: Suppl. 17, 3069-3079.

32 Hasegawa Y, Ando M, Maemondo M, et al. The role of smoking status on the progression-free survival of non-small cell lung cancer patients harboring activating epidermal growth factor receptor (EGFR) mutations receiving first-line EGFR tyrosine kinase inhibitor versus platinum doublet chemotherapy: a meta-analysis of prospective randomized trials. Oncologist 2015; 20: 307-315.

33 Spigel DR, Lin M, O’Neill V, et al. Final survival and safety results from a multicenter, open-label, phase 3b trial of erlotinib in patients with advanced nonsmall cell lung cancer. Cancer 2008; 112: 2749-2755.

34 Hsu CL, Chen KY, Shih JY, et al. Advanced non-small cell lung cancer in patients aged 45 years or younger: outcomes and prognostic factors. BMC Cancer 2012; 12: 241.

35 Sharma SV, Bell DW, Settleman J, et al. Epidermal growth factor receptor mutations in lung cancer. Nat Rev Cancer 2007; 7: 169-181.

36 Shi Y, Au JS, Thongprasert S, et al. A prospective, molecular epidemiology study of EGFR mutations in Asian patients with advanced non-small-cell lung cancer of adenocarcinoma histology (PIONEER). J Thorac Oncol 2014; 9: 154-162.

37 Lohinai Z, Hoda MA, Fabian K, et al. Distinct epidemiology and clinical consequence of classic versus rare EGFR mutations in lung adenocarcinoma. J Thorac Oncol 2015; 10: 738-746.

38 Chang GC CK, Yang TY, Lin SH, et al. Older age may associate with better therapeutic effect of gefitinib in non-small cell lung cancer. J Chin Oncol Soc 2008; 24: 362-371.

39 Yang JCH, Sequist LV, Geater SL, et al. Clinical activity of afatinib in patients with advanced non-small-cell lung cancer harbouring uncommon EGFR mutations: a combined post-hoc analysis of LUX-Lung 2, LUX-Lung 3, and LUX-Lung 6. Lancet Oncol 2015; 16: 830-838.

40 Herceg Z, Hainaut P. Genetic and epigenetic alterations as biomarkers for cancer detection, diagnosis and prognosis. Mol Oncol 2007; 1: 26-41.

41 Yatabe Y, Kosaka T, Takahashi T, et al. EGFR mutation is specific for terminal respiratory unit type adenocarcinoma. Am J Surg Pathol 2005; 29: 633-639.

42 Togashi $\mathrm{Y}$, Hayashi $\mathrm{H}$, Okamoto $\mathrm{K}$, et al. Chronic nicotine exposure mediates resistance to EGFR-TKI in EGFR-mutated lung cancer via an EGFR signal. Lung Cancer 2015; 88: 16-23.

43 Cappuzzo F, Janne PA, Skokan M, et al. MET increased gene copy number and primary resistance to gefitinib therapy in non-small-cell lung cancer patients. Ann Oncol 2009; 20: 298-304.

44 Takeda M, Okamoto I, Fujita Y, et al. De novo resistance to epidermal growth factor receptor-tyrosine kinase inhibitors in EGFR mutation-positive patients with non-small cell lung cancer. J Thorac Oncol 2010; 5: 399-400.

45 Sos ML, Koker M, Weir BA, et al. PTEN loss contributes to erlotinib resistance in EGFR-mutant lung cancer by activation of Akt and EGFR. Cancer Res 2009; 69: 3256-3261.

46 Shigematsu H, Lin L, Takahashi T, et al. Clinical and biological features associated with epidermal growth factor receptor gene mutations in lung cancers. J Natl Cancer Inst 2005; 97: 339-346.

47 Kosaka T, Yatabe Y, Endoh H, et al. Mutations of the epidermal growth factor receptor gene in lung cancer: biological and clinical implications. Cancer Res 2004; 64: 8919-8923. 